\title{
NEAR SURFACE RESISTIVITY AND GEOSTRUCTURAL STUDY OF THE MAHAPELESSA HOT SPRING FIELD, SRI LANKA
}

\author{
H.M.D.A.H. BANDARA ${ }^{1,2}$, N.B. SOORIYARACHCHI ${ }^{1}$, N.D. SUBASINGHE ${ }^{* 1}$ \\ ${ }^{1}$ National Institute of Fundamental Studies, Hanthana Road, Kandy, Sri Lanka \\ ${ }^{2}$ Postgraduate Institute of Science, University of Peradeniya, Peradeniya, Sri Lanka \\ *Corresponding author e-mail: deepal.su@nifs.ac.lk
}

(Received $6^{\text {th }}$ January 2019; Accepted $6^{\text {th }}$ February 2019)

\begin{abstract}
Most of the geothermal hot springs of Sri Lanka are located in the eastern part of the Vijayan Complex (VC) while two springs are found in the Highland Complex (HC), close to the HC/VC boundary zone. Mahapelessa hot spring is the closest hot spring to the $\mathrm{HC} / \mathrm{VC}$ boundary, making it an important landmark in understanding the nature of the $\mathrm{HC} / \mathrm{VC}$ boundary and its impact on the heat sources of the geothermal springs in Sri Lanka. Time Domain Electro-Magnetic (TDEM) survey was carried out at a close proximity to the Mahapelessa hot spring along a traverse extending about $18 \mathrm{~km}$ horizontally across the $\mathrm{HC} / \mathrm{VC}$ boundary zone. A resistivity profile was modelled to understand the shallow subsurface of the terrain. Lithological and structural mapping was carried out in the same terrain to understand the HC/VC boundary and the fracture and joint patterns of the region. Very low resistive zone was indicated in the resistivity profile in the boundary zone and beneath the hot spring. Low resistive zones that run from the hot spring area towards the HC/VC boundary zone were observed. These must be water-bearing deep fractures that transport hot water from the HC/VC boundary, where the heating process occurs.
\end{abstract}

Keywords: Time Domain Electro-Magnetic method (TDEM), Highland Complex (HC), Vijayan Complex (VC), Mahapelessa Hot Spring

\section{INTRODUCTION}

Geothermal springs in Sri Lanka are situated in the Eastern and South-eastern side of the country, loosely associating the boundary between Highland Complex (HC) and Vijayan Complex (VC), extending northward as a $\sim 350$ $\mathrm{km}$ thermal spring line (Dissanayake and Jayasena, 1988) (Fig. 1). These thermal water springs have different flow rates and discharge temperatures, and are located in the low altitude regions ( $<100 \mathrm{~m}$ from the MSL) of the island except for the spring at Marangala, which is located about $100 \mathrm{~m}$ above MSL. The discharge temperatures of springs vary from $39.1^{\circ} \mathrm{C}$ in Rankihiriya) to $62.2^{\circ} \mathrm{C}$ (Nelumwewa) whereas $\mathrm{pH}$ vary from 5.7 (Kanniya) to 8.0 (Kapurella) (Dissanayake and Jayasena, 1988; Fonseka 1994; Chandrajith et al., 2013).

It is generally accepted that the hot water springs in Sri Lanka may not have a direct relationship with volcanic activities, because Sri Lanka is not situated in an active volcanic region or near a major active plate boundary. Recent volcanism is unlikely to be the heat source for the thermal springs (Chandrajith et al. 2013), because available evidence indicates that the last igneous activity in Sri Lanka 
occurred in Jurrasic or late Cretaceous period

(Takigami et al., 1999; Yoshida et al., 1989).

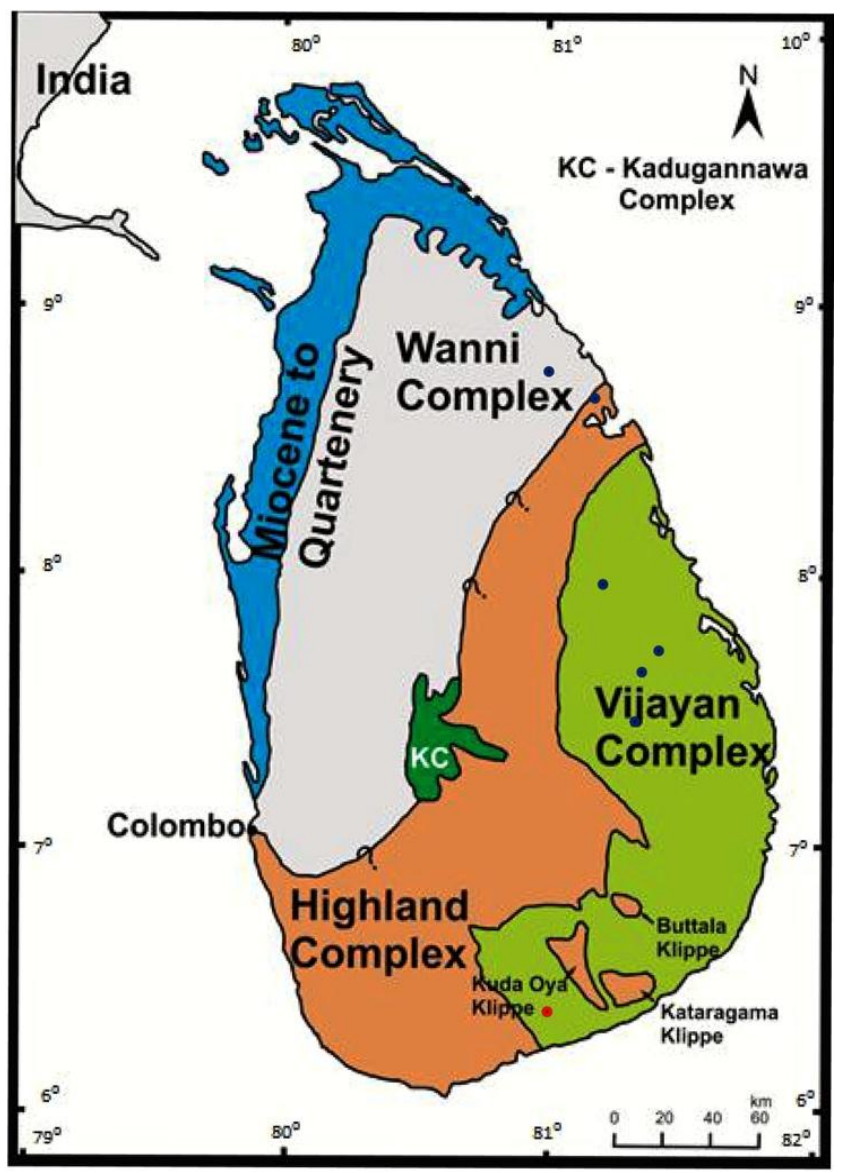

Fig. 1. Geothermal hot springs (marked as blue dots) in generalised geological and tectonic map of Sri Lanka. The location of Mahapelessa hot spring is marked in red (After Cooray, 1994).

Almost all geothermal springs are located close to the boundary between Highland and Vijayan lithological Complexes (Fig. 1). Vithanage (1959) considered this boundary to be a thrust zone, based on the presence of shear zones, wrench faults and mylonites. The thrusting produces the heat in the nature of a deep mantle plume consisting crustal uplift and releasing a thermal flux, producing a high heat zone along the HC- VC boundary, that might have acted as the source for the thermal spring belt (Dissanayake and Jayasena, 1988). Multiple thrust zones and tectonically active zones which are connected with deep seated mega lineament present in the area might have generated heat to increase the geothermal gradient (Premasiri et al., 2006). Neo- tectonic activities along the $\mathrm{HC}-\mathrm{VC}$ boundary, which are also evidenced by micro- seismic activities observed in the Highlands of Sri Lanka, could be due to the slow vertical movement in the Highlands (Fernando, 1983), causing a thermal anomaly by increasing the geothermal gradient (Premasiri et al., 2006). Previous research conducted in Mahapelessa hot spring by Hobbs et al. (2013) suggested that Mahapelessa hot spring is a result of surface water infiltrating from fault zone to deep levels of the earth, which is heated up by normal geothermal gradient and then rising up along the fractures in the shear zones. Magnetotelluric and TDEM resisitivity study done by Nimalsiri et al. (2015) in Kapuralla hot spring in Sri Lanka have identified a low resistive fault zone and interpreted it as the possible geothermal hot water paths feeding the Kapurella hot spring. In a previous study, Subasinghe et al. (2014) have used the TDEM method to identify the near surface resistivity structures for analysing the hot water moving paths from the depth to the spring.

With the presence of serpentine bodies, granites and anomalous uranium bearing regions, some researchers have interpreted the HC-VC boundary as the source of heat for the hot springs (Munasinghe and Dissanayake, 1979). Chemical geothermometers reveal the temperatures of the heat sources of some hot springs close to $150^{\circ} \mathrm{C}$ (Dissanayake and Jayasena, 1988). From the chemical geothermometers of the Na- K- Ca and silica subsurface temperatures calculated for the Kapurella, Mahaoya and Marangala hot springs are around $143^{\circ} \mathrm{C}$, while the same for others are between $102^{\circ} \mathrm{C}$ and $131^{\circ} \mathrm{C}$ (Fournier and Truesdell, 1973).

Although all previous researches describe the physical and chemical characteristics of the hot springs and their possible heat sources, no solid evidence were reported on the occurrence of heat sources. Hence identifying the possible locations or regions of the heat sources would 


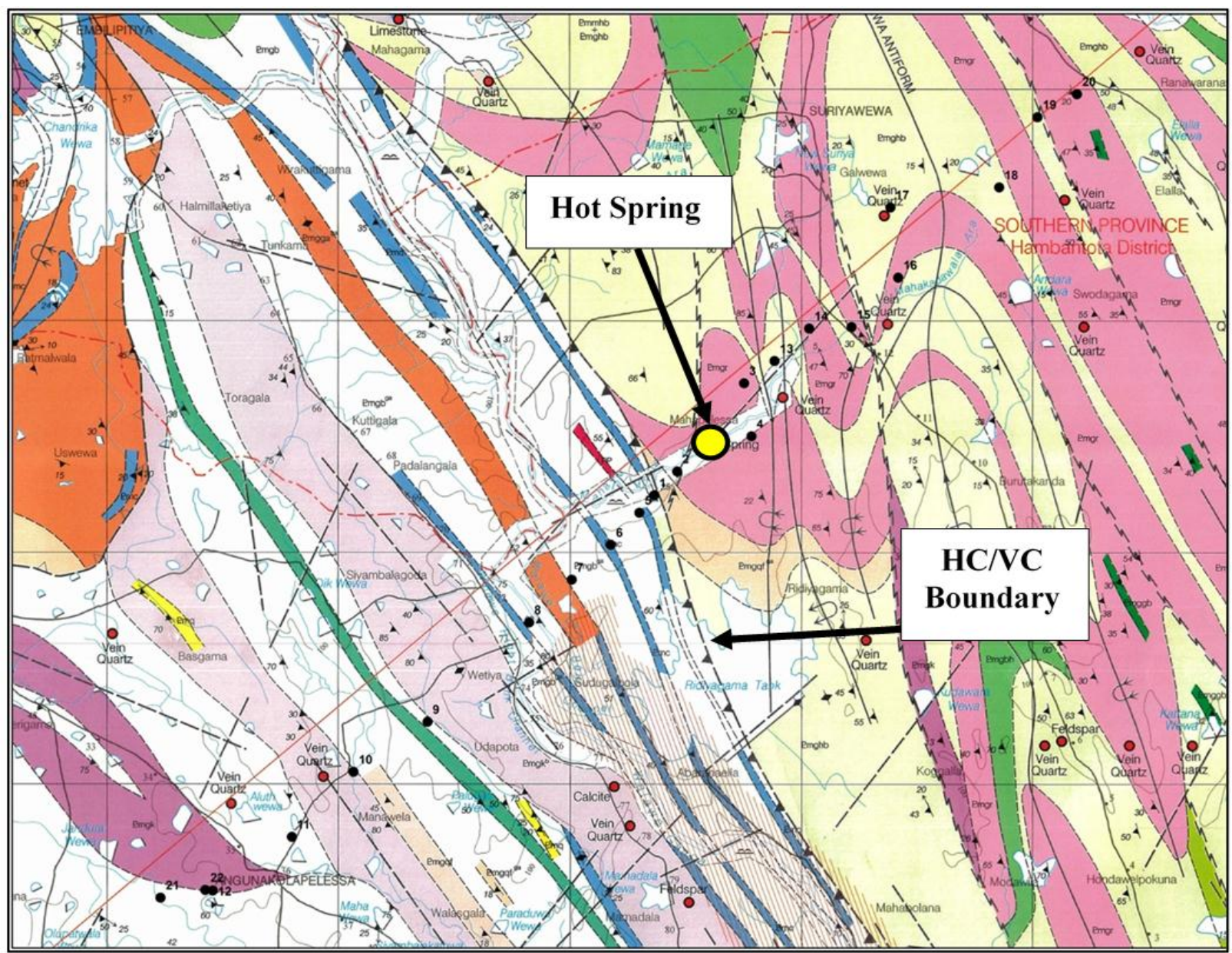

Fig. 2. TDEM survey points (in small black dots) in 1: 100000 Geological map of the area (Published by the Geological Survey and Mines Bureau, Sri Lanka)

be vital for further geothermal studies of the country. Main scope of the present study is to identify the possible region of the heat source and the flow paths responsible for the origin of the Mahapelessa hot spring.

\section{STUDY AREA}

\section{MAHAPALESSA HOT SPRINGS}

Mahapelessa hot spring is located in the Hambanthota District, in the Vijayan Complex with the closest proximity to the Highland Vijayan boundary compared to the other hot springs in Sri Lanka (Fig. 2). Surface temperature of the hot spring is $\sim 44^{\circ} \mathrm{C}$.

\section{METHODOLOGY}

Geological and structural mapping was carried out in the area covering the TDEM survey traverse, cross cutting the HC/VC boundary in southern beach and a line running along the HC/VC boundary zone from Ambalanthota to Angunakolapelessa to understand the lithological and structural characteristics of the terrain. Geonics ${ }^{\mathrm{TM}}$ PROTEM system was used in data acquisition. Processing of the TDEM data was done on Linux based software TEMX, TEMTD, TEMCROSS and TEMRESD, developed by the Iceland GeoSurvey. The TEMX software was used to filter out the noise from the raw data recorded in the Geonics PROTEM system in order to obtain a smooth data curve. The TEMTD was then 
used for model fitting followed by the TEMCROSS using which the profiles were developed. TEMRESD software was used to generate the iso-resistivity maps.

\section{TIME DOMAIN ELECTRO-MAGNETIC METHOD (TDEM)}

The time domain electro-magnetic method (TDEM) is a popular method among geophysicists due to its versatile imaging properties. It is extensively used not only in geothermal exploration, but also in groundwater, mineral and archaeological explorations and for many other purposes involving subsurface studies (Árnason, 1989).

TDEM method is an active electromagnetic method. It uses electromagnetic pulses with known frequency (controlled source) and observes the magnetic response in the receiver (receiver coil). It does not require large power sources (big electrical batteries) or electrical current injecting electrodes for data acquisition. Therefore, data quality is not affected by surface moisture (water) or highly (electrically) resistive zones (eg: rock slabs etc).
Generally, there are three Transmitter loop (Tx loop) and Receiver loop (Rx loop) configurations available for TDEM data acquisition (Fig. 3). During this TDEM survey, central loop method was employed due to its effectiveness and convenience in the field. In the central loop method, Rx loop is placed at the centre of the Tx loop. Both transmitter and receiver (data logger) must be synchronized using a crystal clock (internal clock) or through a synchronization cable. A synchronization cable was used in this work (Fig. 3)

In order to take measurements, transmitter sends DC current pulses to Tx coil and cuts off abruptly after a predetermined time, depending on the Tx frequency. Soon after the turnoff time, the vertical component of the magnetic field is measured at predetermined time gates in respective frequency bands. Magnetic pulses are sent in both directions to avoid polarization of conductive bodies inside the earth. Collection of data was repeated three times (three stacks) to improve data quality and to minimize the methodical errors.

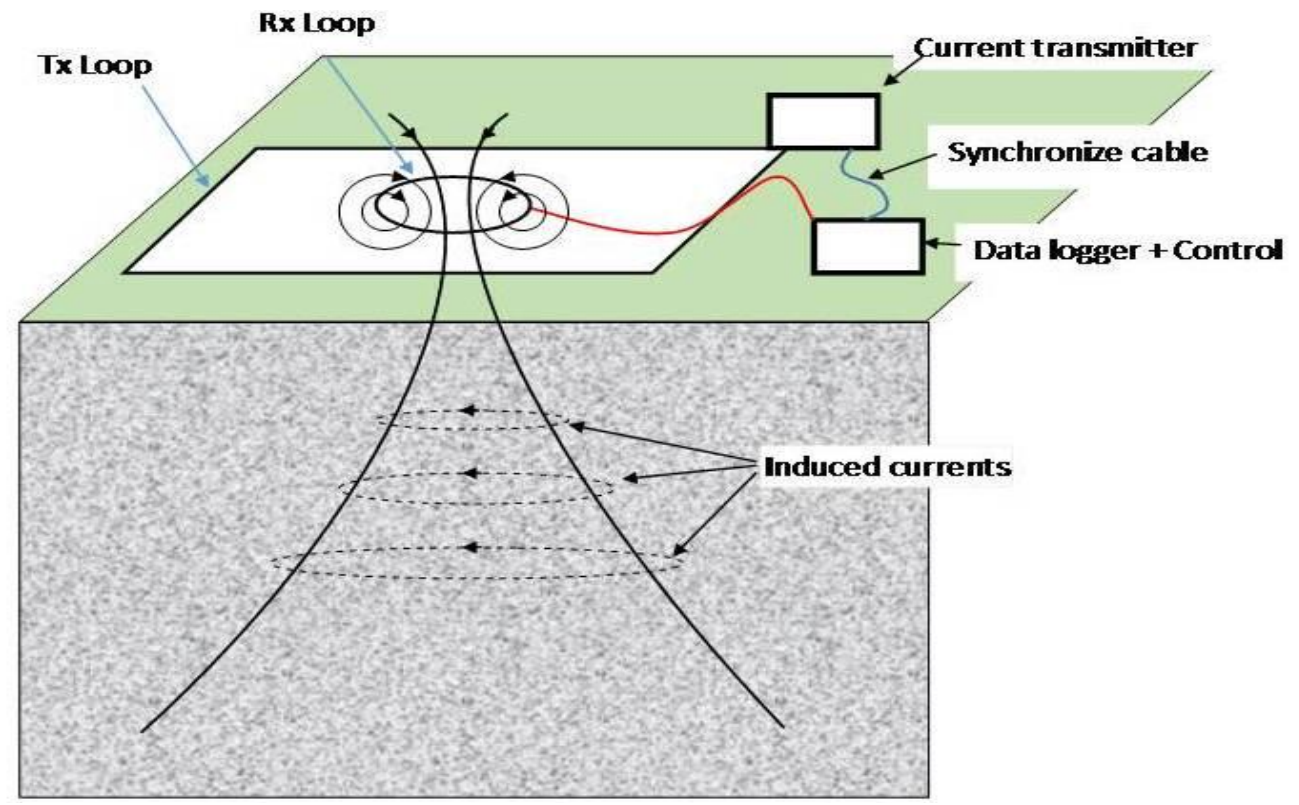

Fig. 3. The central loop Time Domain Electro-Magnetic method (TDEM) field generation 
As the first step of post-processing, voltage response of Rx loop was quality controlled and converted to apparent resistivity using TemX programme (Árnason, 2006a). The output of TemX (apparent resistivity data) was modelled with TEMTD (Árnason, 2006b). this modelled true resistivity data was used to create resistivity cross-sections of the Mahapelessa thermal spring area.

\section{RESULTS AND DISCUSSION}

Rocks such as charnockites and garnet-biotite gneiss belongs to the granulite facies were commonly found at sampling locations in the areas Angunakolapelassa, Ranna, Rekawa and Ussangoda, areas in the $\mathrm{HC}$ side. In the $\mathrm{VC}$ side, in Hambanthota, Kirinda, Madunagala and Sooriyawewa, common rocks are migmatized, granitic, hornblende- biotite, and augen gneisses. Few granulite facies rocks were found in the VC side in Sooriyawewa and Andarawewa, which might be located in the mixed $\mathrm{HC}$ and $\mathrm{VC}$ zone, as interpreted by Kröner et al. (2013).
Out of the 21 survey sites, fourteen (14) survey points in close proximity to the hot spring were selected in order to maintain the clarity of the TDEM profile.

Fig. 4 shows the resistivity cross section at 140 $m$ depth from the Mean Sea Level (MSL) with $18 \mathrm{~km}$ horizontal spread in NE - SW direction. The hot spring is located between points 02 and 04 in Fig. 4.

Highland-Vijayan lithological boundary is located close to the TDEM survey point 01 and the boundary zone is situated between survey points 05 to 02 . A very low resistivity zone is marked on the resistivity profile in that zone, which could be the flow path between deep seated fractures which are filled water and the hotspring on the surface.

Shearing controlled low resistive mineralization can be responsible for low resistivity in close proximity to the $\mathrm{HC} / \mathrm{VC}$ boundary, as suggested by Munasinghe and Dissanayake (1979). Hobbs et al. (2012) and Nimalsiri et al. (2015) also proposed a similar concept after conducting a geophysical survey using MT and TDEM techniques.

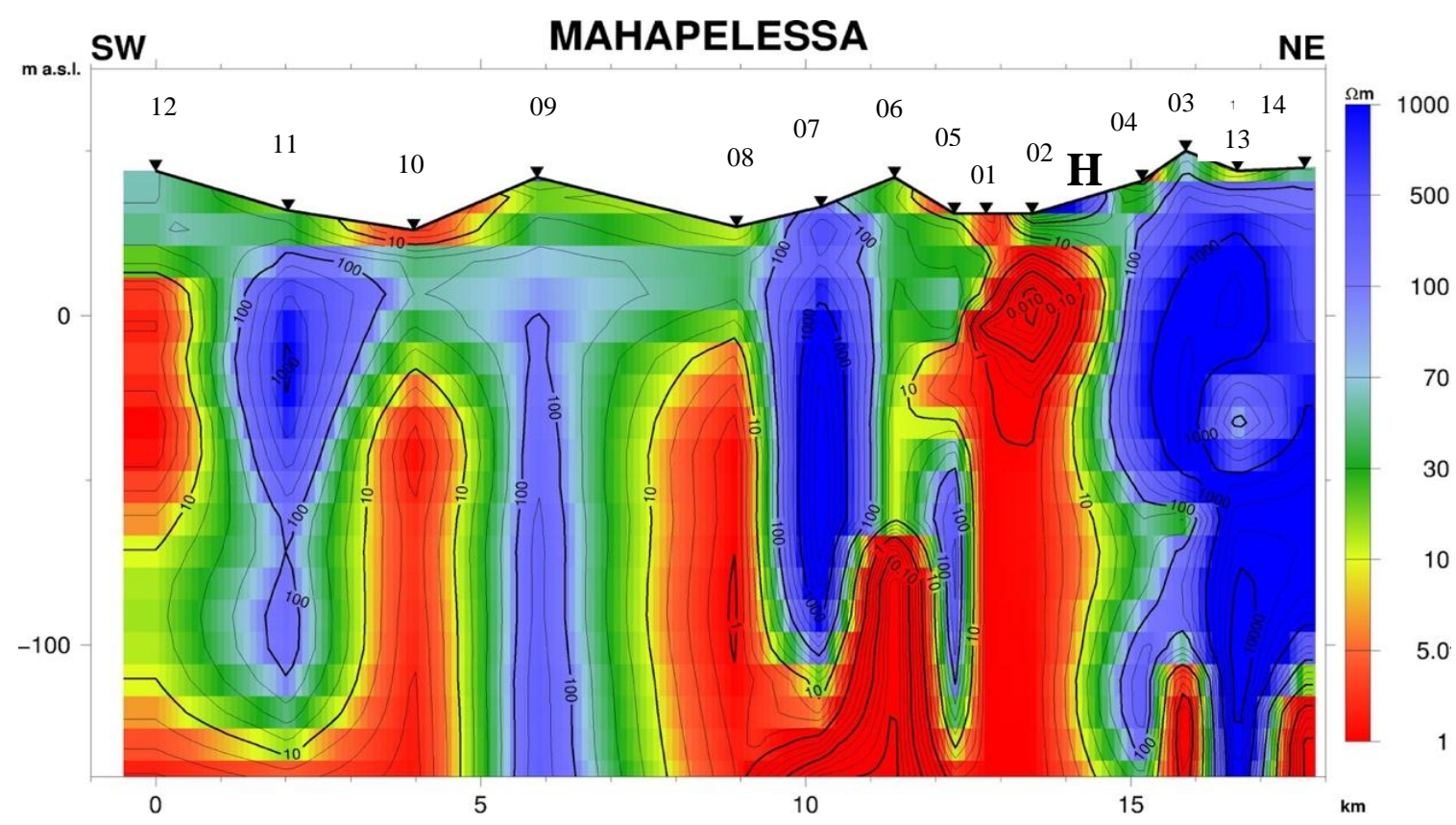

Fig. 4. Resistivity profile of the study area modelled from TDEM results, $\mathrm{H}$ - Hot spring. Small numbers (1 to 14) above the profile indicate the survey points. 

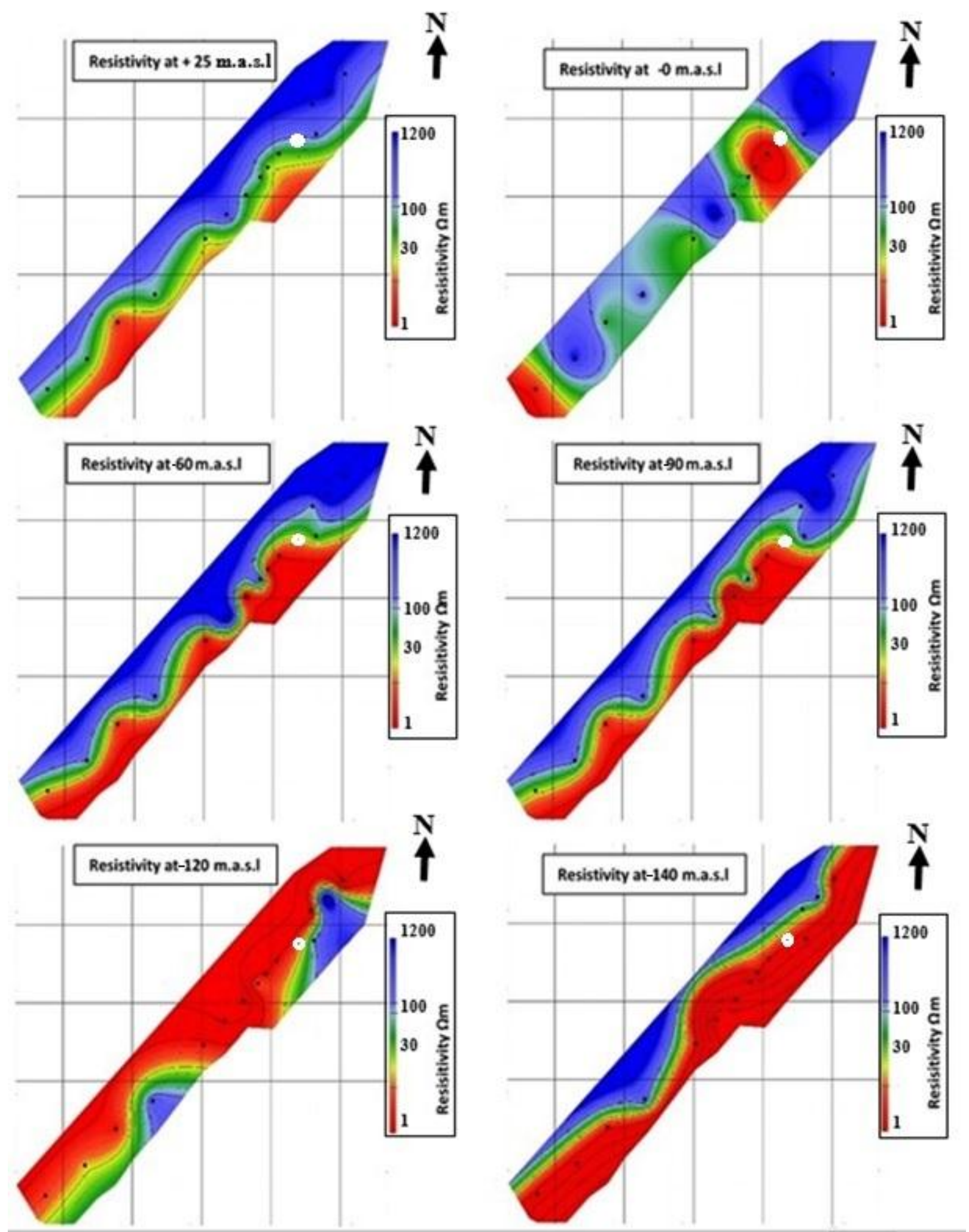

Fig. 5. Iso-resistivity maps of the study area at different depths (the hot spring is marked as a white dot in the upper right part of each map). 
By topographic variations revealed from the resistivity profile close to the hot spring towards SW direction, a valley with approximately $2 \mathrm{~km}$ width is located. There, a low resistive region was (1-70 $\Omega \mathrm{m}$ ) found from the $140 \mathrm{~m}$ beneath MSL to the surface. By comparing with the other low resistive zones in the resistivity profile, this valley might have a connecting flow-path from the deep-seated fracture zones to the surface.

As evidenced from the iso-resitivity maps in Fig. 05, probably the Mahapelessa hot spring is fed from this fracture system starting from Highland-Vijayan complex boundary zone in the SW direction.

In the study of Kapurella thermal spring using Magneto-telluric (MT) and TDEM methods, Nimalsiri et al. (2015) have also identified a fracture or fault zone extending from the SW direction from the depth to the hot spring area. Hence to identify the further extensions of the low resistive zones to deep earth mentioned in this study, MT methods can be applied.

All the iso-resistive maps, except the map corresponds for the 0 mean above sea level (m.a.s.l), show a low-resistive band encasing almost all survey points. Low-resistive band indicated on the surface iso-resistive map possibly due to the surface soil moisture, as indicated similarly in the resistivity profile in Fig.04. Low resistive pocket indicted in the on the 0 m.a.s.l map might be due to the dominant water filled water bearing fracture system, that may be feeding hot water spring. The low resistive band shown in other isoresistive maps may possibly be corresponding to hot and cold water-bearing aquifers and low resistive mineralization in the $\mathrm{HC} / \mathrm{VC}$ boundary zone.

\section{CONCLUSION}

Most of the low-resistive zones in the resistivity profile are in the $\mathrm{HC} / \mathrm{VC}$ boundary zone. The mixed zone, which may be due to the prevalence of water and low resistive mineralization in fractures and joints, is located near the boundary zone. According to resistivity profiles, the thermal spring is directly located above the low resistive zone with less than $10 \Omega \mathrm{m}$, which may possibly be the main thermal water bearing fracture that continued further below. Total $18 \mathrm{~km}$ span is divided into four low-resistive zones by three comparatively high resistive $(>100 \Omega \mathrm{m}$ ) features, which are possibly low permeable rock formations. Low resistive zones are spread more towards the HC/VC boundary, hence the heat source of the Mahapelessa hot spring might possibly be located in the HC/VC boundary or the boundary zone. These preliminary conclusions may be further clarified using more comprehensive techniques such as magnetotelluric (MT) resistivity profiling across the boundary as well as detailed lithological, structural and hydro-geological mapping.

\section{REFERENCES}

Árnason, K., (1989) Electromagnetic central loop transient sounding over a horizontally layered earth. Orkustofnun, Reykjavík, report OS89032/JHD-06, 129pp.

Árnason, K., (2006a) TemX Short manual. ÍSOR Iceland GeoSurvey, Reykjavík, Manual, 17 pp.

Árnason, K., (2006b) TEMTD, a program for 1D inversion of central-loop TEM and MT data. Short manual. ÍSOR - Iceland GeoSurvey, Reykjavík, Manual, 17 pp.

Chandrajith, R., Barth, J.A.C., Subasinghe, N.D., Merten, D., Dissanayake, C.B., (2013) Geochemical and isotope characterization of geothermal spring waters in Sri Lanka: evidencefor steeper than expected geothermal gradients. J. Hydrol. 476, 360-369.

Cooray, P.G., (1994) The Precambrian of Sri Lanka: a historic review. Precambrian Res. 66, 3-18. 
Dissanayake, C.B., Jayasena, H.A.H., (1988) Origin of geothermal systems of Sri Lanka. Geothermics 17, 657-669.

Fernando, M.J., (1983) Microseismic activity in Sri Lanka. Abstr. Symp. Geol. Sri Lanka., 2-3.

Fonseka G.M., (1994) Geothermal system in Sri Lanka and exploration of geothermal energy. Journal of the Geological Society of Sri Lanka, 5, pp 127-133.

Fournier R. O., Truesdell A. H., (1973) An empirical $\mathrm{Na}-\mathrm{Ca}-\mathrm{Ca}$ geothermometer for natural waters. Geochim. Cosmochim. Acta 47, 579-586.

Hobbs, B., Fonseka, M., Jones A., de Silva N., Subasinghe N.D., Dawes G., Johnson N., Cooray T., Wijesundara D., Suriyaarachchi N., Nimalsisri T., Premitallake K.M., Kiyan D., Khoza, D., (2012) Developments for geothermal energy in Sri Lanka: A preliminary magnetotelluric survey of the thermal springs. Jour. Geol. Soc. Sri Lanka. 15, 69-84.

Kröner, A., Rojas-Agramonte, Y., Kehelpannala, K.V.W., Zack, T., Hegner, E., Geng, H.Y., Wong, J.P.M., Barth, M., (2013) Age, Nd-Hf isotopes, and geochemistry of the Vijayan Complex of eastern and southern Sri Lanka: a Grenville-age magmatic arc of unknown derivation. Precambrian. Res. 234, 288-321.

Munasinghe, T., Dissanayake, C. B., (1979) Is the Highland-eastern Vijayan boundary in Sri Lanka a possible mineralized belt? Eco. GEOL., 74, 1495-1496.

Nimalsiri, T.B., Suriyaarachchi, N.B., Hobbs, B., Fonseka, M., Manzella, A., Dharmagunawardena, H.A., Subasinghe, N.D., (2015) Structure of a low-enthalpy geothermal system inferred from magnetotellurics - A case study from Sri Lanka. Journal of Applied Geophysics, 117, 104-110.

Premasiri, H.M.R., Wijeyesekara, D.S., Weerawarnakula, S., Puswewala, U.G.A., (2006) Formation of hot water springs Sri Lanka. ENGINEER, The Institute of Engineers of Sri Lanka 39 (4), 7-12.

Subasinghe, N.D., Nimalsiri, T.B., Suriyaarachchi, N.B., Hobbs, B., Fonseka, M., Dissanayake, C.B., (2014) Study of thermal water resources in Sri Lanka using time domain electromagnetics (TDEM) Advanced Materials Research 955-959, 3198-3201.
Takigami, Y., Yoshida, M., Funaki, M., (1999) 40Ar - 39Ar ages of dolerite dykes from Sri Lanka. Polar Geosci. 12, 176-182.

Vitanage, P.W., (1959b) Geology of the country around Polonnaruwa. Ceylon Geol.Surv. Mem -1.

Yoshida, M., Kunaki, M., Vitanage, P.W. (1989) A Jurassic - Cretaceous Dolarite dyke from Sri Lanka. Journal of Geological Society of India. 33(1), 71-75. 